\title{
Bolts Connection Technique Of Bamboo In Construction Work
}

\author{
Salman Salim ${ }^{1 \mathrm{a}}$,Ahmad Hakimi Mat Nor ${ }^{2 \mathrm{a}}$, MohdErwan Sanik ${ }^{3 \mathrm{a}}$, Mohammad \\ Hairi Osman ${ }^{4 b}$, MohdSufyan Abdullah ${ }^{5 b}$, AbdSukor bin Sarif ${ }^{6 \mathrm{~b}}$ \\ Jenylex Kumil ${ }^{7 \mathrm{c}}$ \\ ${ }^{a}$ Center of Diploma Studies, UniversitiTun Hussein Onn Malaysia, BatuPahat Johor Malaysia \\ ${ }^{b}$ Faculty of Engineering Technology, UniversitiTun Hussein Onn Malaysia, BatuPahat Johor Malaysia \\ ${ }^{c}$ Faculty of Civil and Environmental Engineering, UniversitiTun Hussein Onn Malaysia, BatuPahat Johor \\ Malaysia
}

\begin{abstract}
The construction industry is increasingly developing and growing rapidly with more advanced technologies. The world timber demand is increasing at a rapid rate but the timber supply is however depleting. It has been found through research that bamboo can suitably replace timber and other materials in constructions. This study was conducted to investigate the structural strength of bamboo connections involving only spliced joint and compared with control samples strength of bamboo which were not connected. Bending test was conducted on four types of bamboo connection structures which werehalf-lapped splice joint using 3 bolts, half-lapped splice joint using 2 bolts, side plate splice joint, sleeves and insert joint and control sample bamboo. Every connection had six samples to determine the structural strength of the bamboo connection. From the tests conducted, the maximum load that can be borne by the bamboo structure and the bending ofthe bamboo structure will be obtained. Data were compared with the theoretical calculation based on the study of Janssen's. The connection structure that can bear maximum load was sleeves and inserts which was $5.997 \mathrm{kN}$. The control samples bamboo maximum load was $4.504 \mathrm{kN}$. Meanwhile, half-lapped splice joint using 3 bolts and 2 bolts were $4.789 \mathrm{kN}$ and $4.04 \mathrm{kN}$. Structural connections that carriedthe lowest load was side plate splice joint which was only $2.659 \mathrm{kN}$.Compared with the bending moment of Janssen's theory, all the connections did not exceed the maximum allowable bending moment. This showed that the study was in accordance with the standards approved by Janssen's theory. The study found that the structure of connections that can be used in the construction work was sleeves and inserts.
\end{abstract}

Keywords: Bamboo, bending test, connections

\section{Introduction}

Building materials are increasingly being developed and a lot of research has been done to produce those of high-quality. The use of bamboo in the country has not been exploited and has limited use in the furniture industry and craft[1]. It has been found that some species of bamboo have ultimate tensile strength the same as that of a mild steel at yield point and this coupled with other merits boost the usage of bamboo as construction materials[2]. Bamboo also is a versatile material because of its high strength-to-weight ratio, easy workability and availability [2]. Design's role continued to play the most important role in the structural strength of bamboo. There are many processes and techniques in this connection structure. Fair and efficient consideration should be given a major attention in the bamboo structure that can bear a certain load and move to a more stable structure. The structure of the selected connections must be able to prevent all acts of shear force, lateral force, bending moment and vibration without any form of failure. The strength of the selected connections should exceed the strength of each member that is connected in addition to having a simple design and easy to produce [6].

\section{Literature Review}

Bamboo is one of the building materials that have long been used by humans. Bamboo has been used for a variety of home-grown products for industrial applications such as food containers, sticks, chopsticks, handicrafts, toys, furniture, flooring, pulp and paper, boats, charcoal, musical instruments and weapons. In Asia, bamboo is often used for bridges, scaffolding and housing, but it is commonly used only in the exterior building structure. In the society of people in the tropics, bamboo is the most suitable and affordable material that can fulfill many of their needs in terms of housingelement[3]. Furthermore, bamboo shoots are also an important source of food, a delicacy in Asia. Extractives of the plant can also be used for hair and skin oils, asthma medications, and drug eyewash. Meanwhile, bamboo ash used for polishing gems and manufacturing electric batteries. It has been used on bicycles, windmills, scale, retaining walls, ropes, cables and filament bulb[3].Moreover, bamboo has many other applications. Its usage is very wide. Due to the advancement of science and technology and demand for timber and timber prices higher costs, new methods are needed to 
process bamboo to make it more durable and easier to use in terms ofbuilding materials. Bamboo is one material that can easily be processed, especially if it is split into parts of rods that have been pre-treated with a preservative, is intended to improve the life of the bamboo while not compromising itsstrength[4]. Bamboo trees grow from seeds or rhizomes. Rhizome system is very important for bamboo becausebamboo does not have central trunk as other trees; the system provides a foundation for bamboo rhizomes. Bamboo grows in tropical and subtropical climates. Bamboo is a plant that grows very quickly that it only takes about six months to mature[5].

\subsection{Bamboo Selection}

\section{Materials And Methods}

The selection is based on the type of bamboo reeds that are available in Malaysia. Among the information to be recorded are the outer and inner diameter, thickness and weight of bamboo as shown in Figure 1. Bamboos selected have approximately equaldiameters in order to obtain the data.

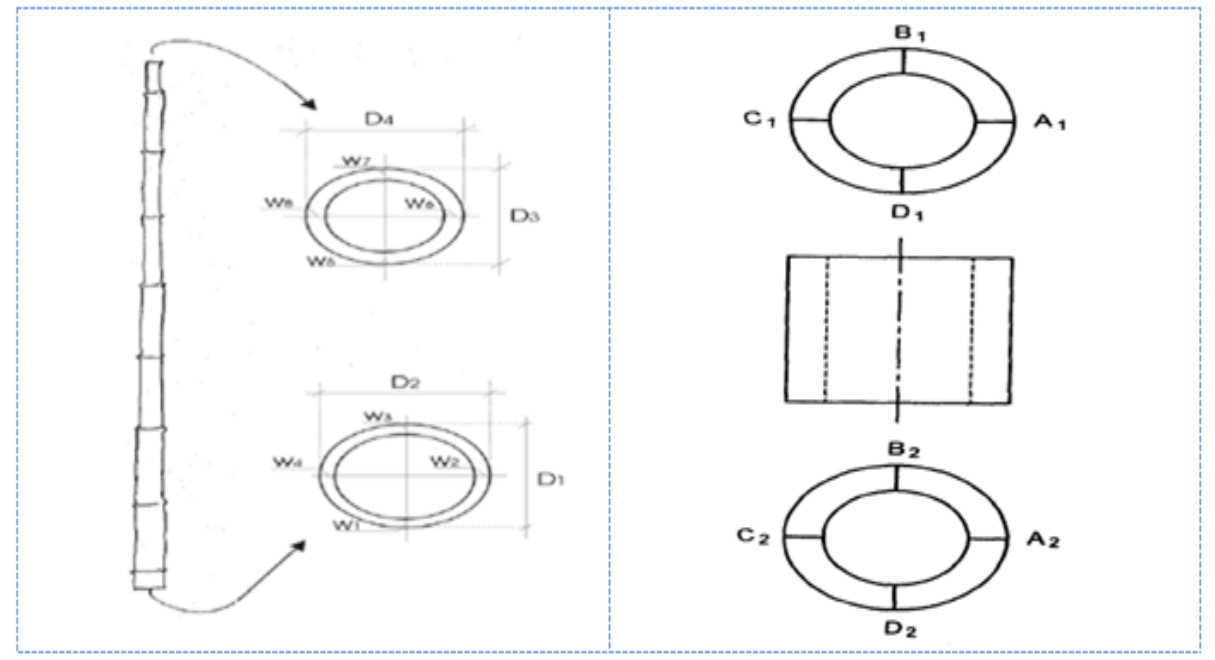

Figure 1: Bamboo outer and inner dimension cross section

\subsection{Sample Preparation}

Figure 2 as shown are four types of connections designed which are(a)half-lapped splice joint using 3 bolts, (b)half-lapped splice joint using 2 bolts, (c)side plate splice joint and (d)bamboo sectional joint. Each connection has six samples to determine the structural strength of the bamboo connections.

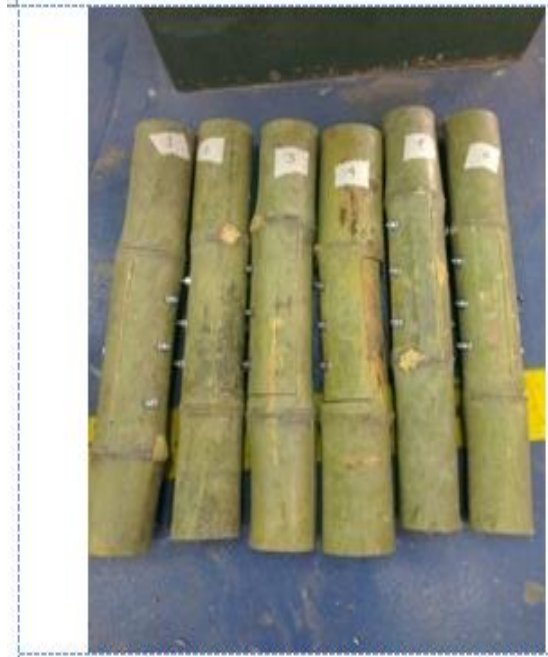

(a): Half-lapped splice joint using 3 bolts

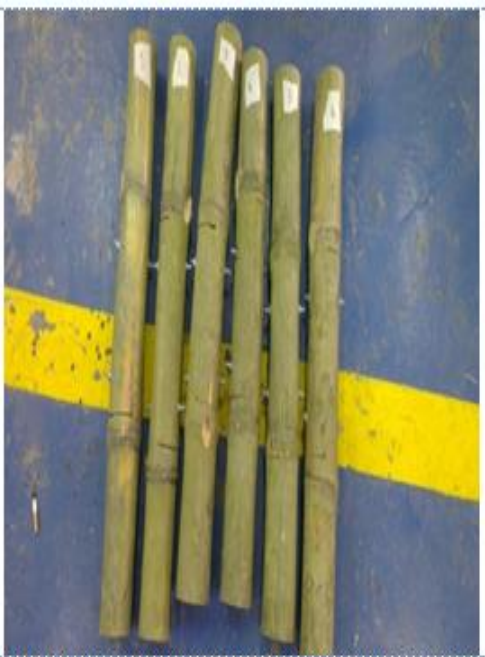

(b): Half-lapped splice joint using 2 bolts

Figure 2: The bolts joint types of bamboo 


\subsection{Bending Test}

The bending tests were carried out on each sample connection. It was to obtain the load capacity that can be supported by the bamboo structural connection on three load points bending test by using the Universal Testing Machine as shown in Figure 3.

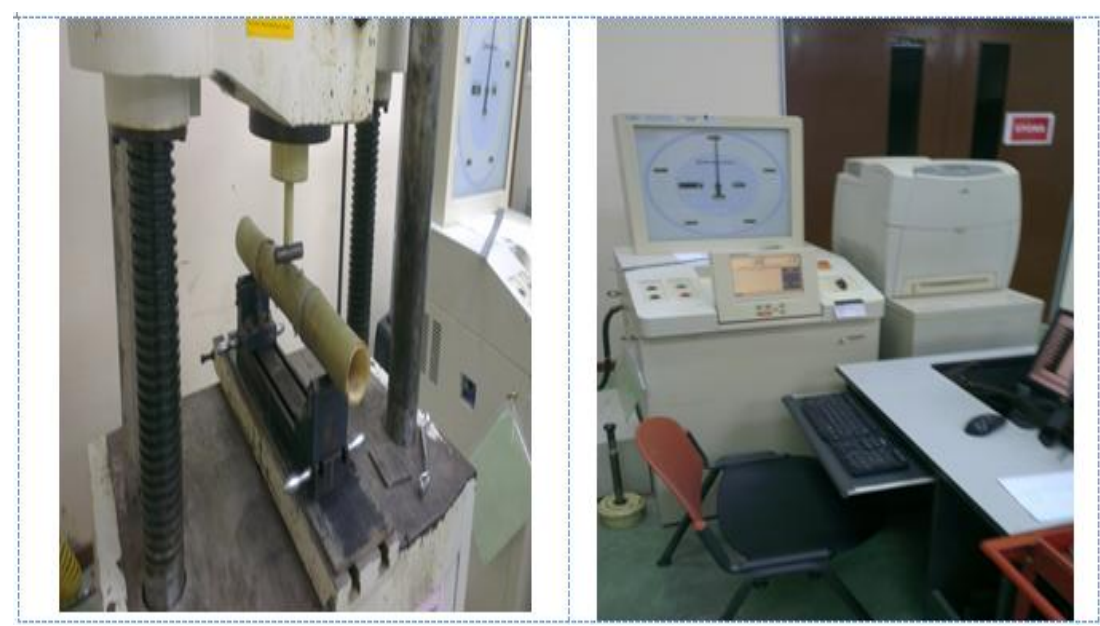

Figure 3: Universal Testing Machine

\section{Results And Discussions}

Table 1 to Table 4 show theresults obtained from tests conducted in the laboratory which are plotted in the graph as shown in Figure 4toFigure 8with the different of the type of connections.

Table 1: Bending test result for half-lapped splice joint using 3 bolts

\begin{tabular}{ccc}
\hline Sample Number & Load $(\mathbf{k N})$ & Deflection $(\mathbf{m m})$ \\
\hline Sample 1 & 2.670 & 9.296 \\
Sample 2 & 5.839 & 9.596 \\
Sample 3 & 4.684 & 19.34 \\
Sample 4 & 6.451 & 9.672 \\
Sample 5 & 3.304 & 8.682 \\
Sample 6 & 5.788 & 10.798 \\
Average & 4.789 & 11.23 \\
\hline
\end{tabular}

Table 2: Bending test result for half-lapped splice joint using 2 bolts

\begin{tabular}{ccc}
\hline Sample Number & Load $(\mathbf{k N})$ & Deflection $(\mathbf{m m})$ \\
\hline Sample 1 & 2.453 & 9.13 \\
Sample 2 & 4.203 & 11.593 \\
Sample 3 & 5.180 & 9.096 \\
Sample 4 & 4.547 & 33.656 \\
Sample 5 & 1.459 & 11.236 \\
Sample 6 & 6.395 & 13.82 \\
Average & 4.040 & 14.76 \\
\hline
\end{tabular}

Table 3: Bending test result for side plate splice joint

\begin{tabular}{ccc}
\hline Sample Number & Load $(\mathbf{k N})$ & Deflection $(\mathbf{m m})$ \\
\hline Sample 1 & 2.077 & 5.500 \\
Sample 2 & 1.605 & 3.310 \\
Sample 3 & 2.738 & 13.868 \\
Sample 4 & 3.314 & 20.743 \\
Sample 5 & 3.564 & 18.226 \\
Sample 6 & 2.656 & 9.162 \\
Average & 2.659 & 11.802 \\
\hline
\end{tabular}

Table 4: Bending test result for control sample bamboo

\begin{tabular}{ccc}
\hline Sample Number & Load $(\mathbf{k N})$ & Deflection $(\mathbf{m m})$ \\
\hline Sample 1 & 5.517 & 10.598 \\
Sample 2 & 6.003 & 8.714 \\
Sample 3 & 3.564 & 8.202 \\
Sample 4 & 3.334 & 5.594 \\
Sample 5 & 4.527 & 5.150 \\
Sample 6 & 4.077 & 7.444 \\
Average & 4.504 & 7.617 \\
\hline
\end{tabular}




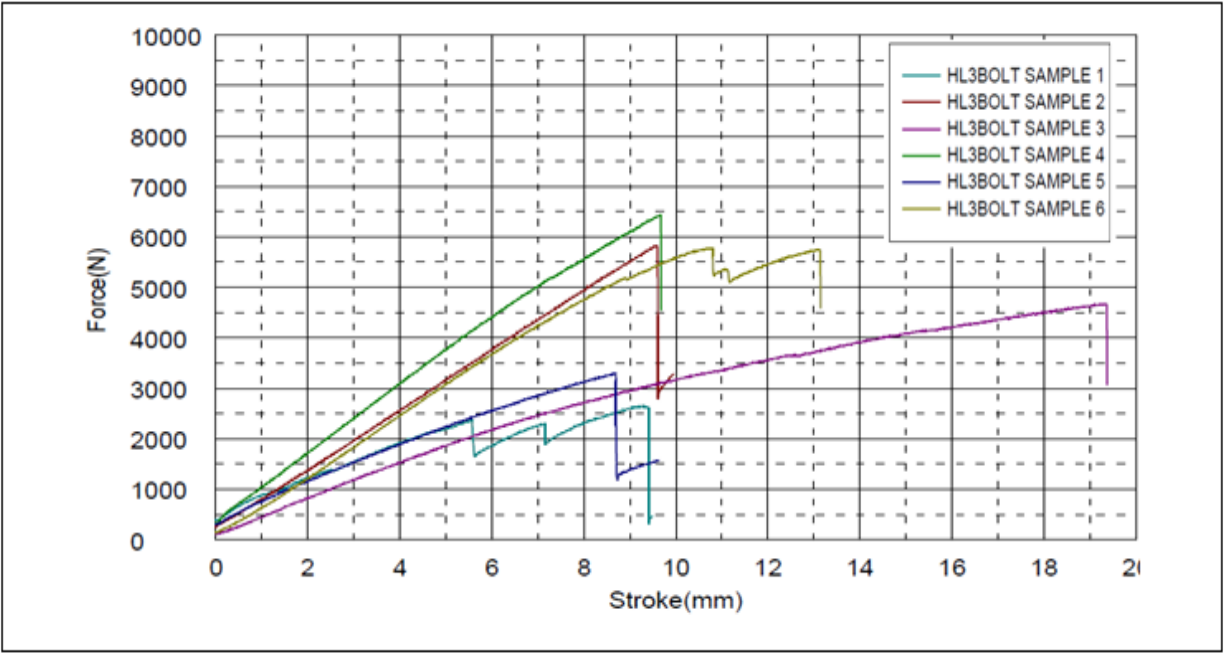

Figure 4: Graph of bending test result for half-lapped splice joint using 3 bolts.

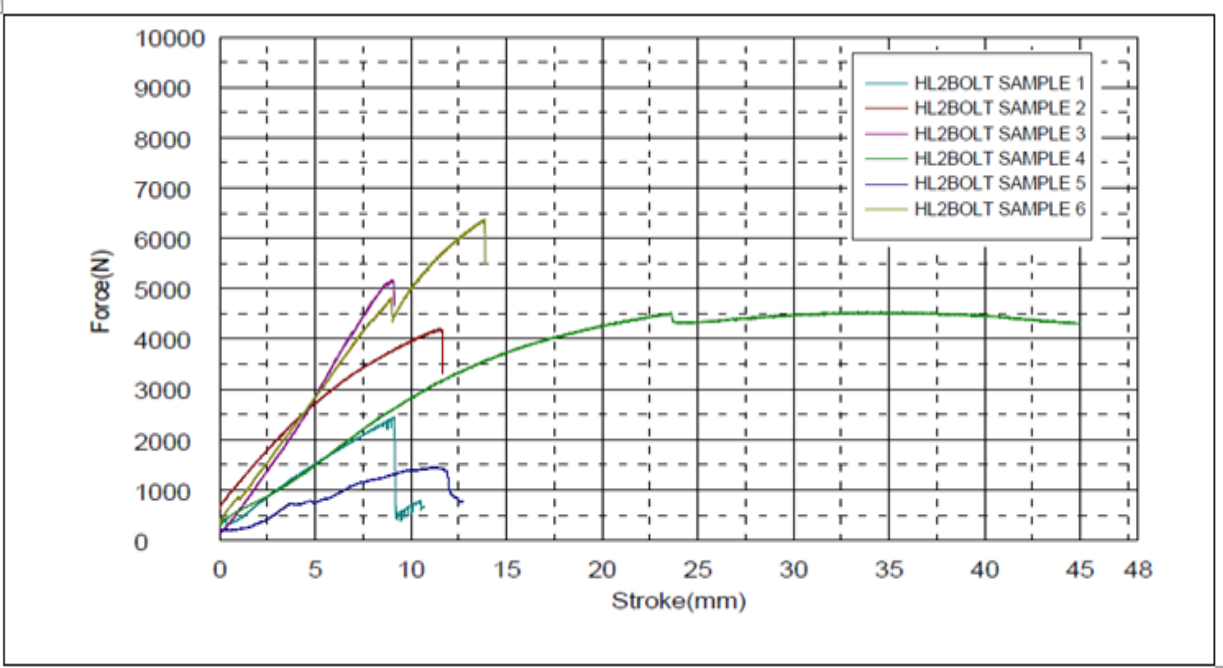

Figure 5: Graph of bending test result for half-lapped splice joint using 2 bolts.

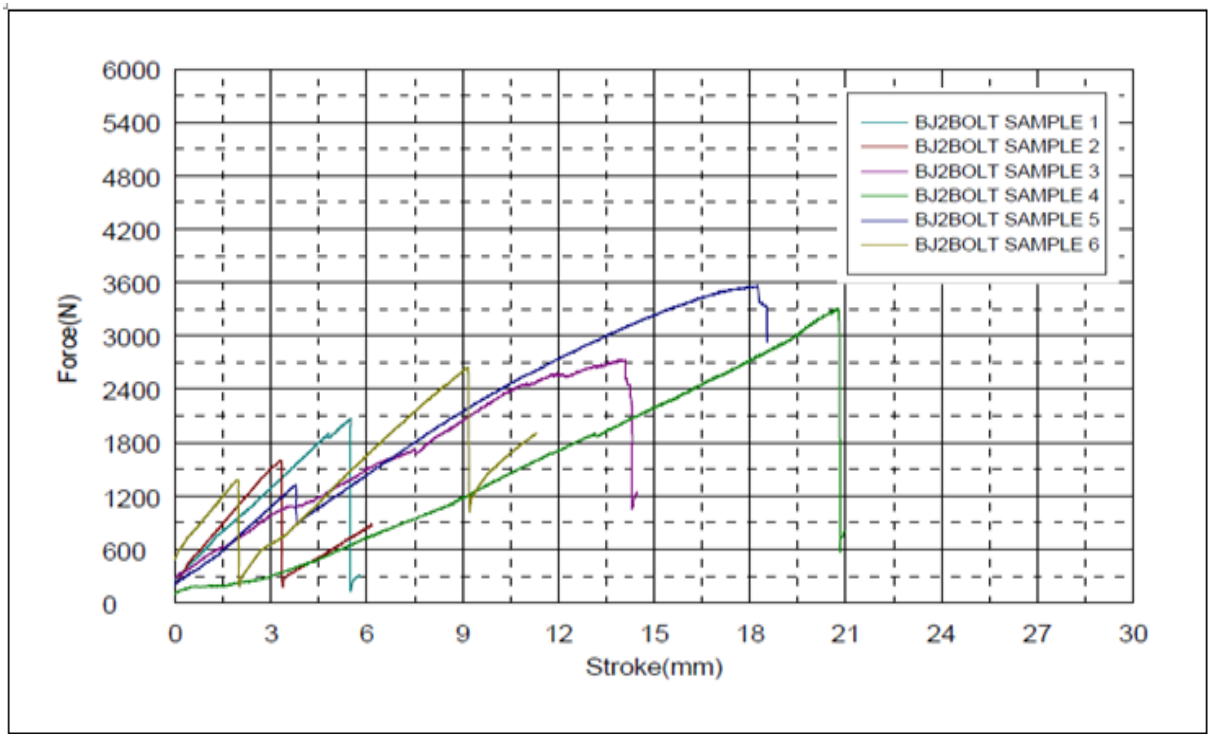

Figure 6: Graph of bending test result for side plate splice joint. 


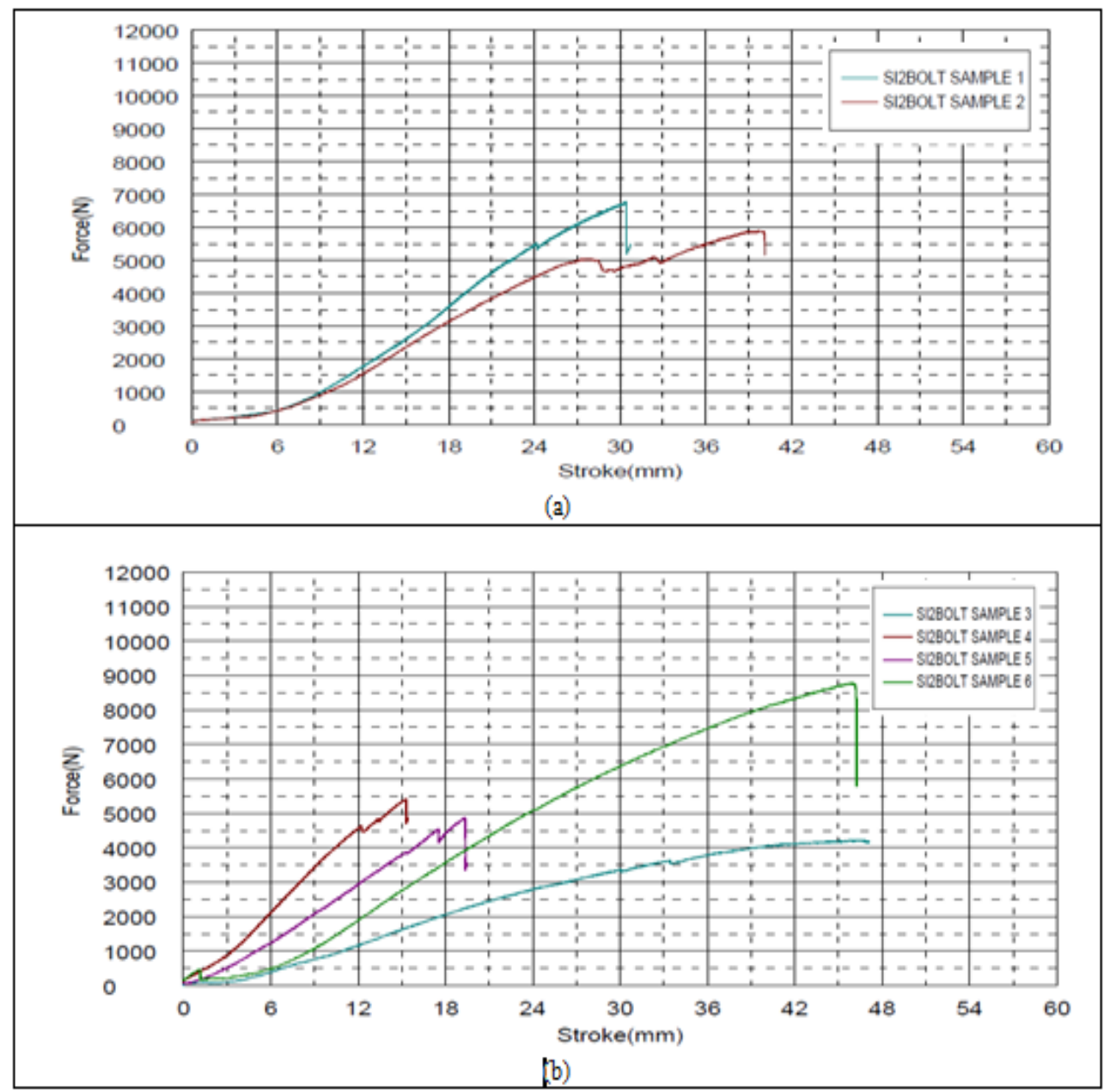

Figure 7: Graph (a) and (b)are bending test result for sleeves and insert joint.

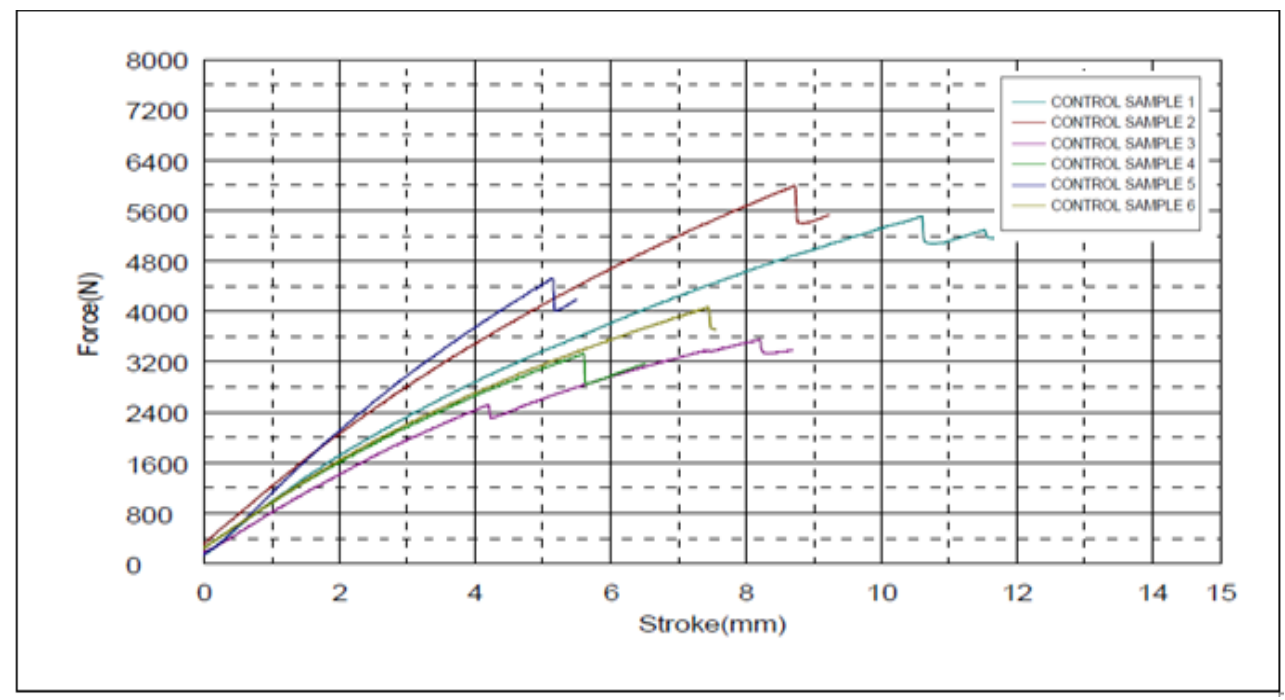

Figure 8: Graph of bending test result for control sample bamboo

\subsection{Comparison between the study result and Janssen's Theory}

Figure 9 shows a comparison between the average values of the bending moment for every type of connection bamboo structure by Janssen's Theory. Referring toJanssen's theory, thehighestbending moment value is the type of connectionside plates.From the experiment, these connections have thelowestbending moment. It occured because the values were affecting the densityandstrengthof the bamboostructure connections. 


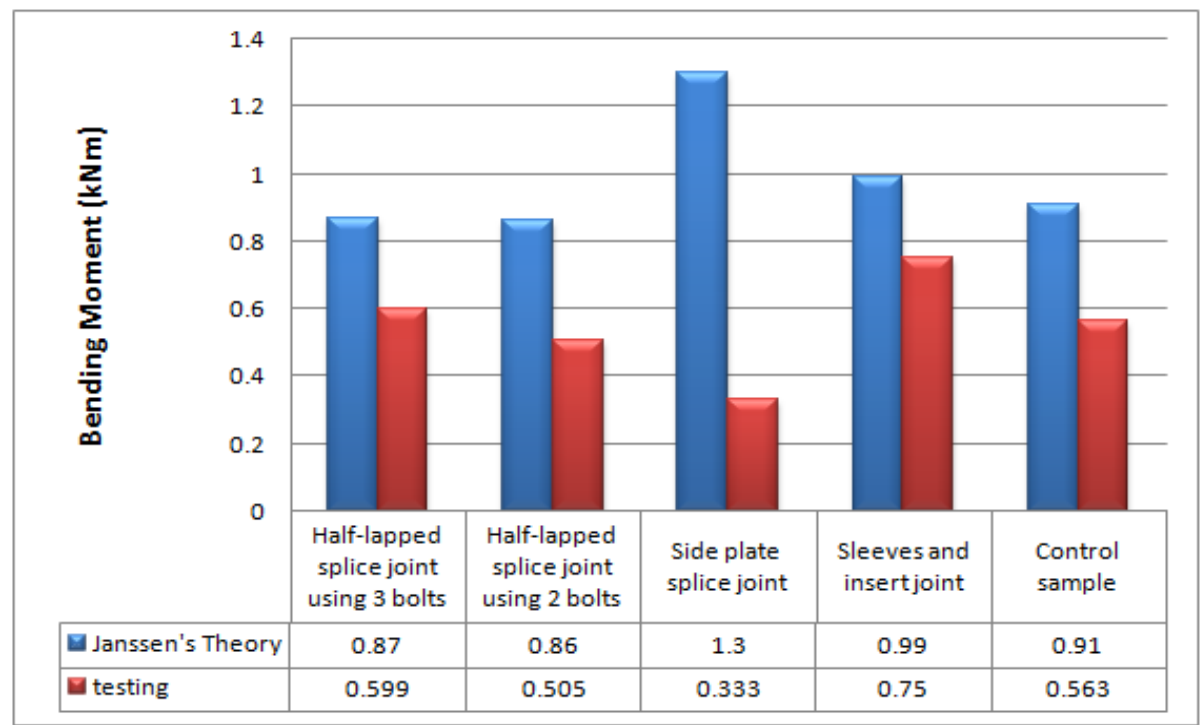

Figure 9: Comparison between bending test result and Janssen's theory

\subsection{Comparison Strength Structure for Each Type of Connection}

Figure 10 shows the average maximum load sustained by the structure of bamboo connection. It shows that sleeves and insert joint has recorded the highest load which was in excess of $5.997 \mathrm{kN}$ maximum load carried by the sample control bamboo. It was found that half-lapped splice joint using 3 bolts bear higher loads than using 2 bolts with the difference of $0.749 \mathrm{kN}$.

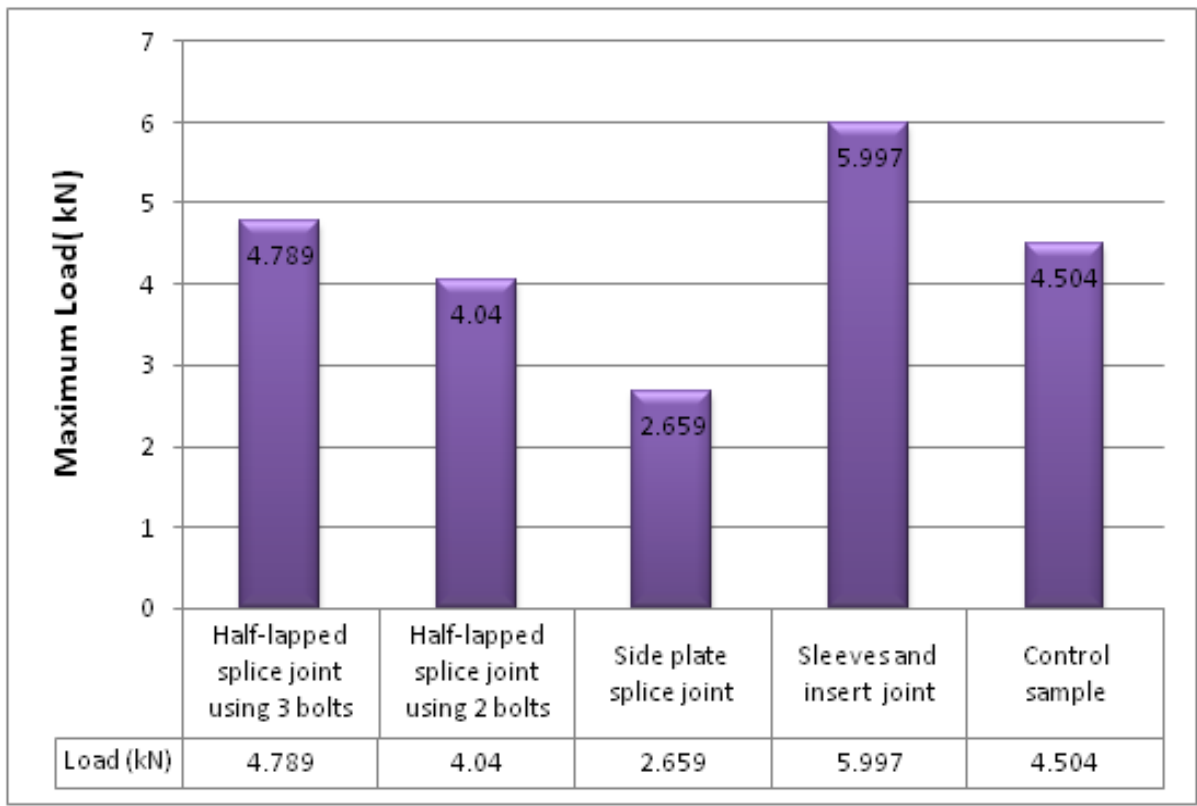

Figure 10: Comparison strength structure for each type

\subsection{Result Discussion}

Based on the results of the bending tests performed on the bamboo connection structure and control sample, it can be concluded that the strongest connection or able to support the highest loads was sleeves and insert joint. This connection was the most powerful because the structure of this connection was only connected by using the smaller size of bamboo structure by inserted it into the bamboo structure and then tied with bolts. It showed that sleeves and insert joint has recorded the highest load which was in excess of 5.997kN maximum load carried by the sample control bamboo. It was found that half-lapped splice joint using 3 bolts bear a higher load which was $4.789 \mathrm{kN}$ than using 2 bolts with just $4.04 \mathrm{kN}$. It can be concluded that using more bolts can caused the bamboo connection structure to support higher loads. 
The 4 types of connection have been tested by using Universal Testing Machine where each connection had 6 samples to determine the strength of the bamboo connection structure. Three-point bending tests were aimed at getting themaximum value of the ultimate load that can be supportedby the structure of bamboo connections. The values obtained from the experiments were compared with the control sample bamboo where the control sample bamboo structure didn't have any connection on it. The bending moment was calculated based on the maximum ultimate load and then compared with the Janssen's Theory.

\section{Conclusions}

As a conclusion, the strength value for the control sample bamboo was $4.504 \mathrm{kN}$. While for half-lapped splice joint using 2 bolts and side plate splice joint, each one's strength was $4.04 \mathrm{kN}$ and $2.659 \mathrm{kN}$ which were lower than the strength of the control sample bamboo. The different with half-lapped splice joint using 3 bolts and sleeves and insert joint, the structure strength was higher than the control sample which were $4.789 \mathrm{kN}$ and $5.997 \mathrm{kN}$. It showed that sleeves and inserts joint were more suitable to be used in construction works. Comparison of the bending moments obtained did not exceed the maximum bending moment that has been calculated based on the characteristic of each connection by using Janssen's Theory.

\section{References}

[1]. Janssen, J.J.A. (1985). The mechanical properties of bamboo. Resent Research on Bamboo. Proceeding of the International Bamboo Workshop Hangzhou, China. Oct. 6-14, 1985.

[2]. McClure, F.A. (1967). The bamboos, Afresh perspective. Harvard University Press.Cambridge, Massachusetts.

[3]. Abd. Latif, M. (1995). Some selected properties of two Malaysia bamboo species in relation to age, height, site and seasonal variation. PHD. Thesis, University Putra Malaysia. 282p.

[4]. Abd.Latif, M. (1993). Effects of age and height of three bamboo species on their machining properties. Journal Tropical Forest Science. 5(4): 528-535.

[5]. Jesse Khong(2012). Growing Bamboo. Stanford University.

[6]. Gianni Bartoli (2005) Performance of Joints in Bamboo Structures. University of Florence. 